\title{
Adrift In Auditing Class
}

\author{
Annhenrie Campbell, California State University Stanislaus, USA \\ Steven Filling, California State University Stanislaus, USA \\ Tim Firch, California State University Stanislaus, USA \\ David H. Lindsay, California State University Stanislaus, USA
}

\begin{abstract}
In 2011, Arum and Roksa challenged the higher education community to examine its practices and improve its performance in Academically Adrift. While recognizing the near universal accessibility achieved by American colleges and universities, the study suggested that students are not learning as well as they should. They measured academic rigor by considering the amount of reading and writing required of students and questioned whether courses are appropriately rigorous. Considering auditing as the accounting course most likely to require writing as well as reading, this study explored the auditing course for the condition of "academic rigor" as defined in the challenge.
\end{abstract}

Keywords: Academic Rigor; Auditing Course; Business Major

\section{INTRODUCTION}

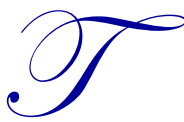

he monograph Academically Adrift issued in 2011 by Richard Arum and Josipa Roksa encouraged reexamination of the state of collegiate learning. The revealing subtitle was "Limited Learning on College Campuses". The authors suggest that colleges do not effectively teach students to "think critically and communicate effectively" and that college classes may not be rigorous enough. That rigor can, in their view, be quantified by considering the amount of reading and writing required of students. Their study used empirical data taken from the CLA (Collegiate Learning Assessment) instrument. Data covered 2,322 students from multiple campuses and was longitudinally evaluated in an attempt to track student learning. The instrument was administered to the subjects twice, two years apart - in 2005 and then 2007. It was subjectively scored to measure the performance and analytical ability of the lower division students from all majors. Additional student data were drawn from transcripts and some institutional measures were considered.

In their key finding, the authors concluded that academic rigor correlates with increased student learning. They believe that the amount of reading and writing required in a particular course can be used as evidence of academic rigor. Although concerned specifically with collegiate learning, the authors believe that earlier (K-12) learning experiences persist and impact the collegiate learning experience (Eskildson, 2011). They, along with many others, recommend better K-12 education which many believe results, at least indirectly, from stronger funding for $\mathrm{K}-12$ programs.

While extolling the achievements of higher education in the United States, Arum and Roksa point out its weaknesses. The ". . . impressive expansion of higher education over the course of the twentieth century has created unprecedented opportunities for access." But ". . . the higher education system as a whole is failing to improve many students' critical thinking, complex reasoning, and writing skills at desirable levels." They suggest that improvements should come from increased reading and writing in class and higher faculty expectations. They believe more "rigor" in coursework and assignments across the board would yield improved learning. However, they recognize that these measures are not easily implemented at a time when class sizes are increasing and faculty are evaluated predominantly with student evaluations (Arum and Roksa, 2011).

In this paper, the authors extend the Arum and Roksa discussion into the accounting program using a survey of auditing professors. In passing, Arum and Roksa observed the growing popularity of the business major 
and noted that many universities actively market the business major as a good choice for potential career success (Arum and Roksa, 2011; Arum, New York Times 5/20/11). They refer generically to the "business major." As business faculty, the authors note that the "business major" encompasses a wide range of subject matter requiring a correlate range of academic skills. From highly quantitative subjects, such as operations management and finance, through more people-oriented or "softer" subjects, such as human resources management, the "business major" covers a variety of specific disciplines. The Accounting program duplicates this range as students need both quantitative skills, as for managerial accounting, and reflective abilities, as in auditing. How applicable might the "academically adrift" discussion be to the accounting study area? Have other accounting faculty considered these issues?

First, a search was conducted to find general reactions in the academic literature and popular press to Academically Adrift. Then the search turned specifically to commentary which addressed the business program and its accounting component. A recap of that review and the results of a questionnaire subsequently devised after considering that literature follow.

Because the original Arum and Roksa study so emphasized writing as one measure of - and means of attaining what they term "rigor", this work focused on the auditing course and the auditing faculty. The expectation was that the auditing course would be most similar across various programs since students prepare for the same uniform CPA (Certified Public Accountant) examination. The authors expected the course would include a significant reading and writing component as students apply written audit standards to audit cases they are asked to evaluate. The Arum and Roksa "academically adrift" study simply did not focus on objective or quantitative academic topics such as those more likely to be encountered in the other courses in the Accounting program.

This should be considered a preliminary and exploratory study. The questionnaire was designed to collect the opinions and responses of accounting faculty nationwide to the issues identified in the "academically adrift" discussion. Fifty-nine responses were received for a $15 \%$ survey response rate after contacting accounting faculty at those U.S. colleges and universities listed with five or more accounting faculty in the Hasselback directory (20112012).

\section{LITERATURE REVIEW}

Arum and Roksa intended to start a discussion about learning in higher education and their monograph is being taken seriously. Discussion is widespread and has appeared in the popular as well as academic press. Even reviewers who criticize the monograph's methodology agree that its points have been widely demonstrated and the discussion it encourages is important (Murphey, 2011). It led at least one college president to attend a day's worth of classes as a student to see exactly what is going on (Colleen, 12/11/11). The description of higher education provided by Arum and Roksa is substantiated by a detailed and scholarly discussion explaining how the current state of higher education has evolved and what the future holds (Ehrenberg, 2012).

Peer reviewed journals provided about one-fifth of the articles addressing the "academically adrift" phenomenon, some addressing the business school environment. In some cases, comments relevant to the discussion of academic rigor were incidental to the point of an article while, in other cases, the Arum and Roksa monograph was directly addressed. Arum and Roksa participated in a symposium dedicated to discussing Academically Adrift that was reported in a 2011 edition of the journal Society (Arum and Roksa, 2011). The journal devotes each issue to a symposium on one social sciences topic covering, as noted on its webpage description, "new ideas and research findings." The popular press and internet have also covered the discussion with most of the relevant literature simply bemoaning the current situation in higher education.

Most commentators agree that the current situation for collegiate education is not as good as it could be and often discuss how this situation evolved. Everyone seems to agree that college costs are rising both from the student and the institutional perspectives (Broulliette, 2011; Burka, 2012) and that the search for affordability for the one and funding for the other often overwhelms the educational mission. Funding constraints on colleges, including reduced endowment earnings and reductions in public funding, have forced institutions to focus on their own survival by marketing their product and otherwise enhancing revenues (Harkness, 6/1/12). 
Most commentators and faculty accept institutional accreditation as evidence of quality. One study trying to understand why colleges seek accreditation for various programs, such as AACSB accreditation of the business school, explains that accreditation provides public assurance of the very commitment to quality that Arum and Roksa suggest is weakening in higher education (Brink and Smith, 2012).

The academically adrift problem could result from the failure of K-12 education (Morgan-Thomas, 2012) and was briefly mentioned in terms of an institution's responsibility to help all its students stay in school in an empirical study of freshman retention (Bass and Ballard, 2012). A comparative study of learning outcomes suggests it may lead to a less informed and prepared electorate and higher corporate demand for foreign-trained specialists and graduate degrees throughout the economy (Farazmand and Green, 2012).

After mastering the basic mechanics of reading in the K-6 experience, high school students should have learned how to extract meaning by reading in various subject areas. Students studying the advanced topics they encounter in college need to have developed a strong foundation in reading comprehension at the K-12 level (Morgan-Thomas, 2011). Better K-12 teaching materials may be needed to achieve these desired improvements (Murphey, 2012).

Arum and Roksa identified the business major as both heavily marketed to undergraduates and possibly lacking in academic rigor. An ethical discussion of the marketing of the business school itself references Arum and Roksa's concerns (Natale and Doran, 2012). In their rigorous analysis of college recruitment, they note that colleges appear to regard students as consumers. Colleges seem more concerned with the revenue stream represented by the students as consumers than with the quality of the service being delivered. If regarded as consumers, it is questionable whether there currently are adequate "consumer protections" represented, perhaps, by outcomes measures. Arum and Roksa suggest that regarding students as consumers leads to deterioration of educational quality. Natale and Doran, by examining the resulting ethical issues, point out that education is not a product that can easily be returned as defective. If your credential does not represent adequate training, what consumer protections are there for the higher education "product?"

Students may internalize their role as "consumers" and regard good grades as an entitlement, a possibility supported by the observation of increasing litigious behavior regarding grades (Baehr, 2011). They are learning how to succeed by being lazy rather than by working hard (Matthews, 2012). Most agree that college life currently involves a lazy student culture and institutions that treat the student as a consumer. It's possible that students would become more engaged if they were involved in course design and might opt for more rigorous work if they could help structure it (Childs, 4/4/11).

While endorsing the Arum and Roksa findings, Vedder, in a blog post in the Chronicle of Higher Education, came to a somewhat different conclusion (2011). Increased access to higher education may have diluted the experience for all students. However, college is still worthwhile for employment opportunities as well as for the learning experience (Vedder, 2011). The college experience has changed over time from a contemplative activity for upper-class scholars to an employment training experience for the general student (Slosburg, 1/21/11).

In an interesting British case study, the career decisions of two business students were examined in depth to see both their attempts to ready themselves for work after graduation, and their relative success at it. The study found them "professionally adrift", unsure of how to improve their job prospects, or even exactly what kind of work they would like (Greenbank, 2012).

While many agreed that the business major might be a less challenging choice, some recognized that some of its component disciplines, such as accounting and finance, could hardly be considered easy choices (Glenn, 2011). In the business school, and closer to the topic of this study, Arum and Roksa were cited as motivation for an analysis of the cognitive performance of accounting students (Ravenscroft et al., 2012). It has long been felt that the CPA exam assures that accounting students complete some minimal level of rigorous study. Kerr (2011) suggests that the CPA exam can be used only so far as a rationale for imposing rigor in accounting courses and that most students may be concerned mostly with accumulating the requisite credits so they can take the exam itself. 
One study argues that accounting students require more from their courses than just preparation for professional exams. They need to learn how to be self-directed learners and how to assess their own ability and progress. This returns to the issue of assessment, though in the guise of self-assessment. As an argument for rigor in the accounting program, the practice of accounting requires continual updating and learning (Ravenscroft et al., 2012).

At the 2011 symposium, Attewell defended the book but agreed that the CLA measure it used might be flawed and added perspective to the findings. Some students specifically come to college to drift. Others who choose career-oriented majors carefully manage their exposure to classes or experiences that could reduce their GPA. While employers say they want strong critical thinking skills, they habitually choose business school graduates and winnow prospects by GPA (2011). Employers may initially choose on the basis of GPA but may depend more on observation of students as interns or probationary employees. Students may work harder before college to get in and after college to keep their job than they do in college where they may drift and enjoy the experience (Winship, 2011).

Typically, the business major provides higher salaries than liberal arts, although the liberal arts studies may actually provide more practice at "critical thinking" (Attewell, 2011). In fact, the lesser reading requirements of the business major comprise one of its main attractions for both students and institutions (Shaw, 2/5/13).

Colleges and universities probably did not mean for their consumer orientation to lead them to compete with each other for students and their dollars. Seeing students as consumers was clearly argued in Arum and Roksa as contributing to the observed lack of rigor. However, as state support to institutions diminished in relation to the support directly available to students, competition for students was an obvious outcome. Students are less likely to choose on the basis of faculty research or rigor and more on the basis of grading and access to good employment after graduation (Tuchman, 2011).

Professors might be more willing to enforce critical thinking activities in class if their promotion were based less on student evaluations. However, if promotion is based more heavily on research, professors may tend to place less effort and importance on the teaching activity (Kelly-Woessner and Woessner, 2011). Emphasis on research could simply distract professors from teaching (Rose, 2011; Tuchman, 2011). Some suggest that research which challenges tenure-track professors may encourage "rigor" in all their work including teaching (KellyWoessner and Woessner, 2011). On the other hand, a less rigorous course might demand less of both the professor and the students and allow the professor to spend more time on research (Rose, 2011).

The importance of research in hiring and retention decisions is not likely to diminish as research tends to be easily counted and reported (McClatchy-Tribune, 2/7/11). Research may be used to market to prospective students or donors (Bass and Ballard, 2012). That research, in fact, may be skewed to the needs of large donors and away from the content of the teaching (Baehr, 2011).

In any case, there may be something of a pact between professors and students in which students provide reasonable evaluations of teaching, which is admittedly hard to measure, and professors provide acceptable grades. Teaching effectiveness is challenging to measure (Rose, 2011). Further, student satisfaction measures implicitly regard the student as "consumer". The professors most popular with the students might be providing the least benefit (Overall, 2012). However, finding and improving outcomes measures circles the discussion back to the measurement challenges faced by Arum and Roksa.

The College Board's estimates show that the lifetime value of the college degree, such as it may be, still exceeds its cost although these numbers could reflect an overestimate by society of the intrinsic value of the education (Wood, 2011). College is very costly and those costs are continually increasing (Broulliette, 2011; Burka, 2012). If graduates are often unemployed, is college worth this cost (Ferguson, 2012; Mcgurn, 11/1/11; Rosenhall, 6/9/11; Wood, 2011)? Is college a valuable investment and can the return to the student be quantified (Reimer, 11/71/11)? Nearly half the sources expressed concern on the return value of college cost. They also agree that the situation is unlikely to change so long as the credential earned in college leads to jobs after graduation. 
An additional, somewhat contrarian, perspective voiced at the 2011 symposium held that students have always been lazy, so this shouldn't be a surprise. There really is no crisis in higher education because, if useless, there would be no market reward for holding a credential. Students have always been casual about their studies and, in any case, are probably learning valuable work skills such as punctuality. Further, if the education they receive is just not adequate, then employers will hire from abroad and the market will correct the issue (Weissburg, 2011). Schools whose graduates simply cannot succeed will not attract students.

Although the Arum and Roksa theses were widely accepted, the specific measures used were widely questioned. Arum and Roksa indicated they considered the results of the National Survey of Student Engagement in constructing their variables and evaluating their data (Arum and Roksa, 2011). However, this may be a weak defense of their data collection as the NSSE is more concerned with non-academic satisfaction measures than learning outcomes measures (Jaschik, 1/18/11). The difficulty of developing reliable empirical data for their study led the authors to recommend the development of improved outcomes measures directed at student learning. Murphey (2011) noted that the CLA instrument covered only a tiny proportion of American college students and did not assess subject-specific skills, an issue that might be of concern to accounting professors. The CLA is subjectively scored and uses a fairly generalized scoring rubric, but it is a direct measure of student learning while surveys are indirect measures. However, survey data can be refined and may provide useful although indirect assessment information (Douglass et al., 2012). Improvements in direct assessment measures should be accompanied by survey research. Surveys can add to the usefulness and improve the interpretation of new and better assessment measures (Douglass et al., 2012). Not all studies need to be as large as the CLA. Case studies and other small studies can also be useful (Greenbank, 2012).

Given the increasing cost of higher education and its burden on both students and institutions, assessment of its value becomes more important (Shaw, 5/22/11). Perhaps, in addition to learning, outcomes assessments should include resulting employment and earnings. More and better assessment of outcomes at each level would facilitate the improvements needed. Not just learning outcomes, but measurements of other dimensions, such as employment and pay, are needed (Coates and Morrison, 2013). A hopeful sign is that research about learning outcomes appears to be increasing (McClatchy, 2/7/11).

Results could also be clouded because there is such a variety of student motivation. While some are at college for academics and skill-building, others just come for the experience. As noted earlier, there can be a motivation for students to avoid the same challenging courses that would enable them to increase their learning outcomes (Attewell, 2011).

Today's culture contributes to the decline in academic rigor bemoaned by Arum and Roksa. It's not just a problem in the classroom (Green, 2011). No one reads as much as they once did (Matthews, 2012). Yet, college should be preparing students for citizenship (Kitzmiller, 2012). It could really just be the credential, not the underlying skills, that the students require (Lehrer, 4/28/12). Students may actually be learning the skills they really need to survive, but these are not being tested or measured (Mcardle, 2012). Students may not be working hard in college, but perhaps they're willing to work later on the job (Slosburg, 4/25/11; Winship, 2011). Students may be learning to succeed without working that hard on their studies (Wall Street Journal, 2/10/11)

Of the specific Arum and Roksa recommendations, there is wide agreement about the need to improve K12 education, although there is less agreement as to how this might best be achieved. Better K-12 education would help students build better study habits and they would be more likely to have clearer goals for their career path (Carey, 2013). Better K-12 preparation would support college outcomes and college success may simply be a proof of adequate K-12 preparation (Bialik, 2011). Better reading skills are key to developing critical thinking skills as students need first to be able to read the information before they can analyze it (Morgan-Thomas, 2012). Accounting students' reading skills, therefore, also need to be upgraded for improved critical thinking (Weissburg, 2011)

\section{THE STUDY}

This exploratory study was undertaken to understand how the assertions in Academically Adrift and the resulting discussion are relevant to the accounting teaching area by surveying faculty in accounting programs. 
Because the original Arum and Roksa study strongly associated academic "rigor" with writing assignments, the focus was on the auditing course and the faculty teaching that course. Many programs have research and writing courses, but these vary a great deal from program to program. The auditing course was chosen as the accounting course that is most likely to have a significant writing component and also most likely to share similarities across schools.

The authors contacted the faculty member identified in the Hasselback Accounting Faculty Directory (2011-2012) as primarily teaching the auditing course. Faculty from U.S. colleges and universities having at least five faculty members were contacted using "Survey Monkey." Fifty-nine responses representing a response rate of $15 \%$ were received. The questions and responses are as follows:

\begin{tabular}{|c|c|c|c|}
\hline Yes/No Questions & yes & no & n \\
\hline $\begin{array}{l}\text { Does your university have an upper division writing course requirement associated with the } \\
\text { student's major? }\end{array}$ & $49.2 \%$ & $50.8 \%$ & 59 \\
\hline $\begin{array}{l}\text { If there is a writing course requirement associated with the student's major, is there a preceding } \\
\text { writing proficiency assessment such as an exam or a required course? }\end{array}$ & $45.8 \%$ & $54.2 \%$ & 48 \\
\hline $\begin{array}{l}\text { Does your university require students to pass an upper division writing proficiency exam after } \\
\text { completing upper division writing proficiency classwork? }\end{array}$ & $8.5 \%$ & $91.5 \%$ & 59 \\
\hline $\begin{array}{l}\text { At your university, do you have one or more upper division accounting courses specifically } \\
\text { associated with the university writing proficiency requirement? }\end{array}$ & $38.6 \%$ & $61.4 \%$ & 57 \\
\hline If so, is the auditing course a course associated with the writing requirement? & $36.4 \%$ & $63.6 \%$ & 44 \\
\hline $\begin{array}{l}\text { Do research and writing assignments in the auditing course either parallel the new CPA exam } \\
\text { research and writing portion, or are they intended to prepare students for this portion of the CPA } \\
\text { exam? }\end{array}$ & $33.3 \%$ & $66.7 \%$ & 54 \\
\hline In your opinion, does your program offer adequate writing practice? & $46.3 \%$ & $53.7 \%$ & 54 \\
\hline
\end{tabular}

\begin{tabular}{clc}
\hline $\begin{array}{c}\text { Rank } \\
\text { Question }\end{array}$ & $\begin{array}{c}\text { In The Auditing Course, What Percentage Of Student Time, Both In And Out Of Class, } \\
\text { Is Spent On The Following Activities? (Total Is Greater Than 100\%) }\end{array}$ & Amount \\
\hline 1 & - Lecture and discussion & $26.4 \%$ \\
\hline 2 & - Reading & $25.1 \%$ \\
\hline 3 & - Other & $16.9 \%$ \\
\hline 4 & - Structured audit cases & $12.6 \%$ \\
\hline 5 & - Exams, quizzes & $12.4 \%$ \\
\hline 6 & - Unstructured case/research/term paper & $12.0 \%$ \\
\hline 7 & - Team problem-solving & $8.9 \%$ \\
\hline 8 & - Other writing assignments & $7.5 \%$ \\
\hline 9 & - Team presentations & $4.0 \%$ \\
\hline
\end{tabular}

\begin{tabular}{|c|c|c|}
\hline $\begin{array}{c}\text { Rank } \\
\text { Question }\end{array}$ & $\begin{array}{l}\text { In The Auditing Course, What Percentage Of A Student's Grade } \\
\text { Is Earned On The Following Activities: (Total Is Greater Than 100\%) }\end{array}$ & Amount \\
\hline 1 & - Exams, quizzes & $62.4 \%$ \\
\hline 2 & - Other & $17.7 \%$ \\
\hline 3 & - Structured audit cases & $14.2 \%$ \\
\hline 4 & - Unstructured case/research/term paper & $13.8 \%$ \\
\hline 5 & - Other writing assignments & $13.0 \%$ \\
\hline 6 & - Lecture and discussion & $8.5 \%$ \\
\hline 7 & - Team presentations & $8.5 \%$ \\
\hline 8 & - Team problem-solving & $7.3 \%$ \\
\hline 9 & - Reading & $3.5 \%$ \\
\hline
\end{tabular}




\begin{tabular}{cccccc}
\hline \multicolumn{4}{c}{ Of The Writing Assignments In The Auditing Course, The Proportion } & That Explicitly Address Ethical Issues Is: \\
\hline Very Small & Small & Medium & Large & Very Large & Responses \\
\hline $13.5 \%$ & $28.8 \%$ & $44.2 \%$ & $13.5 \%$ & $0.0 \%$ & 52 \\
\hline
\end{tabular}

\begin{tabular}{|c|c|c|c|c|c|}
\hline \multicolumn{6}{|c|}{$\begin{array}{l}\text { Of The Writing Assignments In The Auditing Course, } \\
\text { The Proportion That Requires Students To Explain Conceptual Issues Is: }\end{array}$} \\
\hline Very Small & Small & Medium & Large & Very Large & Responses \\
\hline $5.6 \%$ & $14.8 \%$ & $50.0 \%$ & $24.1 \%$ & $5.6 \%$ & 54 \\
\hline \multicolumn{6}{|c|}{$\begin{array}{l}\text { Of The Reading Assignments In The Auditing Course, The Proportion That Are Persuasive, } \\
\text { Confrontational Or Thought-Provoking Rather Than Intended Simply For Absorption And Later Reproduction Is: }\end{array}$} \\
\hline Very Small & Small & Medium & Large & Very Large & Responses \\
\hline $9.3 \%$ & $33.3 \%$ & $37.0 \%$ & $20.4 \%$ & $0.0 \%$ & 54 \\
\hline
\end{tabular}

\begin{tabular}{cccccc}
\hline \multicolumn{4}{c}{ In Your View, Is The Proportion Of Student Writing In Auditing Decreasing, Staying The Same Or Increasing? } \\
\hline $\begin{array}{c}\text { Decreasing } \\
\text { Dramatically }\end{array}$ & Decreasing & Staying The Same & Increasing & $\begin{array}{c}\text { Increasing } \\
\text { Dramatically }\end{array}$ & Responses \\
\hline $1.9 \%$ & $11.1 \%$ & $59.3 \%$ & $27.8 \%$ & $0.0 \%$ & 54 \\
\hline
\end{tabular}

\begin{tabular}{cccccc}
\hline \multicolumn{4}{c}{ Based On Your Experience, How Much To Do Believe Your Students' Future Employers Value Writing Skills? } \\
\hline Not At All & Very Little & Somewhat & A Fair Amount & A Great Deal & Responses \\
\hline $0.0 \%$ & $0.0 \%$ & $8.9 \%$ & $28.6 \%$ & $62.5 \%$ & 56 \\
\hline
\end{tabular}

\section{CONCLUSIONS}

The survey results indicate that accounting programs generally do offer some writing practice, although many faculty believe there should be more of it. As expected, much of the writing assigned to accounting majors was found in the auditing course. While there was wide variability in how much writing practice actually occurred in auditing courses from one institution to another, the amount of writing in each course appears to be stable over time.

Faculty do not indicate that writing in the auditing course is claiming an increasing proportion of the students' time and efforts. It is possible that the need to study an increasing body of authoritative literature reduces the time available for writing activities. It's also possible that more and better course materials need to be developed to facilitate writing assignments. It's also likely that accounting and auditing professors may feel unprepared to edit and grade students' written work.

The grading schemes in place did not seem to reflect the proportion of the students' time spent on written work. This could be a problem if writing is seen by educators as important because students may perceive less importance if less of the grade depends on it. As an aside, student writing in auditing seemed more likely to involve conceptual rather than ethical issues.

Strikingly, the study revealed that faculty believe that students' future employers highly value their writing skills, but only a minority of programs formalize upper division writing skills development. This suggests that students acquire writing practice as an incidental benefit within their courses. The design of auditing courses shows that reading comprises about a quarter of the students' efforts and writing much less and a relatively smaller proportion, respectively, of the grade is earned from each activity.

The authors believe the accounting program, because of the existence of a long-standing and regarded outcomes measure, the CPA exam is ideally suited for discussions about the quality of teaching and learning, about faculty performance, and about measuring learning outcomes. The pass rate and subsequent professional success of graduates can be expected to reflect on the quality of the overall program. 
Additional study is needed to understand whether more writing would be beneficial in the accounting program, as suggested by the Arum and Roksa thesis. If beneficial, what materials should be made available to accounting faculty and further, how can appropriate training and support be provided?

\section{AUTHOR INFORMATION}

Dr. Annhenrie Campbell, Ph.D. University of Colorado, has edited CPA exam materials and researched the relationship of CPA exam pass rates with faculty and institutional characteristics. Email: ACampbell1@ csustan.edu (contact author).

Dr. Steven Filling, Ph.D. University of Iowa, developed the upper division writing and research course for the Accounting concentration of the College of Business Administration. Email: SFilling@csustan.edu.

Pr. Tim Firch, J.D. University of California at Davis, teaches accounting research. His research interests focus on collegiate writing programs. Email: TFirch@csustan.edu.

Dr. David Lindsay, Ph.D. Kent State University, is a prolific researcher in the areas both of financial performance and academic performance. Email: DLindsay@csustan.edu.

\section{REFERENCES}

Arum, R., \& Roksa, J. (2011). Academically Adrift: Limited Learning on College Campuses. The University of Chicago Press, Chicago IL.

Arum, R. (2011). Diluted Degrees. N. Y. Times, 5/20/11.

Arum, R, \& Roksa, J. (2011). Limited Learning on College Campuses. Society, 48(3): 203-207.

Attewell, P. (2011). Riddle Remains in Academically Adrift. Society 48(3): 225-226.

Baehr, P. (2011). Purity and Danger in the Modern University. Society 48(3): 297-300.

Bass, L. H., \& Ballard, A. S. (2012). Student engagement and course registration methods as possible predictors of freshman retention. Research in Higher Education Journal, 18 (December, 2012): 1-13.

Bialik, C. (2011). U. S. News-THE NUMBERS GUY: A College Test Leaves Questions Unanswered. Wall Street Journal, Section A2: 1/22/11.

Brink, K. E., \& Smith, C. A. (2012). A Comparison of AACSB, ACBSP, and IACBE Accredited U. S. Business Programs: An Institutional Resource Perspective. Business Education and Accreditation. 4(2): 1-15.

Broulliette, M. (2011). Penn State University Paupers? Pshaw! Central Penn Business Journal, 27(13) (March 25): 16,18 .

Burka, P. (2012). Storming the Ivory Tower. Texas Monthly (October).

Carey, K. (2013). The Next Affirmative Action. The Washington Monthly 45(1-2) (January, February): 55-57.

Childs, W. (2011). Mcdaniel students help design the classes they're taking. McClatchy-Tribune Business News $4 / 4 / 11$.

Coates, K., \& Morrison, B. (2013). The Graduate's Million Dollar Promise. Maclean 's, 126(2) (January 16): 42.

Colleen, P. K. (2011). SMC's President tries being a College Student for a day. Spartenburg Herald-Journal $12 / 11 / 11$.

Douglass, J. A., Thompson, G., \& Zhao, C. (2012). The Learning Outcomes Race: the Value of Self-Reported Gains in Large Research Universities. Higher Education 64(3) (February 4): 317-335.

Ehrenberg, R. G. (2012). American Higher Education in Transition. The Journal of Economic Perspectives, 26(1) (Winter): 193-216.

Eskildson, L. E. (2011). Book Review: Academically Adrift McClatchy-Tribune Business News 1/20/11.

Farazmand F. A., \& Green, R. D. (2012). Applied Projects: Learning Outcome Differences between Senior and Sophomore-Junior Students. Journal of Case Studies in Accreditation and Assessment. 5(1): 1-14.

Ferguson, N. (2012). Who Needs College? Higher Education is Becoming the new Caste System. Newsweek 160(10) (September 3).

Glenn, D. (2011). The Default Major: Skating Through B-School. N. Y. Times, 4/14/11.

Green, R. (2011). Rick Green Column, Hartford (Connecticut) Courant. Mcclatchy-Tribune Business News 2/1/11. 
Greenbank, P. (2012). Career-Decision-making by Business School Students: A British Case Study. International Journal of Management, 29(4) (December 2012): 543-553.

Harkness, P. (2012). Public Universities Reach Tipping Point after Years of Decreased Education Funding. Mcclatchy-Tribune Business News, 6/1/12.

Hasselback, J. R., Hasselback/Accounting, A Directory of Accounting Faculty, Academic Year 2011-2012, webpage accessed 11/10/13: a book review of Arum and Roksa (Murphey). 34/e.

Jaschik, Scott. (1/18/11). Study finds large numbers of college students don't learn much, Inside Higher Education, an online publication, www.insidehighereducation.com accessed 6/15/14.

Kelly-Woessner, A., \& Woessner, M. (2011). Promoting a "House of Study". Society 48(3) p. 227-231

Kerr, S. G. (2011). A Note of Caution: The International CPA Designation. American Journal of Business Education, 4(6) (June): 39-44.

Kitzmiller, F. (2012). Wofford Initiative examines value of Liberal Arts Degree, find College is Preparing Students Well. Spartanburg Herald-Journal 2/14/12.

Lehrer, J. (2012). Review-Head case: Taking Knowledge out of College. Wall Street Journal 4/28/12.

Matthews, J. R. (2012). Assessing Library Contributions to University Outcomes: The Need for Individual Student Level data. Library Management 33(6): 389-402.

Mcardle, M. (2012). The College Bubble: Mythomania about college has turned getting a degree into an American neurosis. Newsweek 160(12) (September 17).

Mcclatchy-Tribune Business News. (2011). You're in College. So Learn. Debate about our Campuses. 2/7/11.

Mcgurn, W. (2011). What's Your Kid Getting from College? Occupy Wall Street has a point about student debtsort of. Wall Street Journal 11/1/11, accessed 11/11/13.

Morgan-Thomas, M. (2012). The Legal Studies Case Brief Assignment: Developing the Reading Comprehension Bridge to Critical Thinking. International Journal of Business and Social Science, 3(23) (December): 75 85.

Murphey, D. D. (2011). Book Review: Academically Adrift. Journal of Social, Political and Economic Studies, 36(4) (Winter) 498-505.

Murphy, T. H. (2012). Nutrisoya v. Sunrich: Anatomy of a Sales Dispute. Journal of Leadership, Accountability and Ethics, 9(1): 11-18.

Natale, S. M., \& Doran, C. (2012). Marketization of Education: An Ethical Dilemma. Journal of Business Ethics 105(2): 187-196.

Overall, M. (2012). College Courses Need Slacker Index Mcclatchy-Tribune Business News. 4/16/12.

Ravenscoft, S. P., Waymire, T. R., \& West, T, D. (2012). Accounting Students' Metacognition: The Association of Performance, Calibration Error, and Mindset. Issues in Accounting Education, 27(3) (February): 707-732.

Reimer, S. (2011). The Baltimore Sun Susan Reimer Column. Mcclatchy-Tribune Business News (November 7).

Rose J. (2011). The Age of Aphasia. Society, 48(3): 531-538.

Rosenhall, L. (2011). California Teen Entrepreneur asks: College? Who Needs it? Mcclatchy-Tribune Business News 6/9/11.

Shaw, J. S. (2013). Higher learning, Meet Lower Job Prospects; Outrage greets a Governor who dared to suggest that college degrees should lead to employment. Wall Street Journal Online 2/5/13 accessed online $11 / 11 / 13$.

Shaw, J. S. (2011). Universities can’t be Exempt from our Shared Sacrifice. Spartanburg Herald- Journal (May 22).

Slosburg, T. (2011). Commentary: The Tyrannies of Unexamined Options. The Idaho Business Review 1/21/11 accessed 11/11/13.

Survey Monkey, free online survey tool: https://www.surveymonkey.com/.

Tuchman, G. (2011). The Unintended Decentering of Teaching and Learning. Society 48(3): 216-219.

Vedder, R. (2011). Academically Adrift, a Must Read. Chronicle of Higher Education, blog post, 1/20/11, accessed $11 / 10 / 13$.

Wall Street Journal. (2011). Now College is the Break. Wall Street Journal 2/10/11. accessed 11/11/13.

Weissberg, R. (2011). Is American Higher Education All that Bad? Society, 48(3): 220-224.

Winship, C. (2011). The Faculty-Student Low-Low Contract. Society, 48(3): 232-235.

Wood, P. (2011). The higher Education Bubble. Society, 48(3): 208-212. 
NOTES 